\title{
Research on the Relationship between Maintenance Time and Examination Time of Patents
}

\author{
Yongzhong Qiao ${ }^{1, a}$, Hao Peng ${ }^{1, b}$ \\ ${ }^{1}$ Intellectual Property Research Institute, Xiamen University, Xiamen, 361005, P.R.China \\ a1562899518@qq.com, b573273824@qq.com
}

Keywords: Patent, Maintenance Time, Examination Time

\begin{abstract}
Based on the maintenance and examination information of granted 3838 patents in 1994 by SIPO, this paper draws some conclusions after concrete analysis. Firstly, the maintenance time is negatively related to the examination time. Secondly, the maintenance times of most patents are 1-3 years and the examination times of most patents are 2-5 years. Thirdly, when the examination time of a patent is between 2 years and 5 years, the maintenance time of this patent will be longer, especially in 4 years, compared to other examination time. Then, this paper researches the reasons of above conclusions from the point of patent protection period, the financing policy, the market conditions and the patent censor system. In the end, this paper makes suggestions how to extend maintenance time of patent.
\end{abstract}

\section{Introduction}

Since patent system has been implemented in China from 1985, the patent work has realized leapfrogging development. Since the utility model patent and design patent can be granted without substantive examination, the influence factor of the utility model patent and design patent maintenance time always is random. So in this paper, patent only refers to the invention patent. According to statistics, SIPO has accepted 4580173 applications of domestic patents by October 2015 with year-on-year growth of 22.4\% in 2014. Meanwhile SIPO has accepted 1479850 applications of foreign patents with year-on-year growth of 5.3\% in 2014. By October 2015, the domestic valid patent quantity is 877535 , while the foreign valid quantity is 538991 . The domestic quantity of application, authorization, increment and validation is far better than in foreign countries. In conclusion, China has become a patent country.

The quantity of patent doesn't represent the quality of patent. The maintenance time is a significant standard of the quality of patent. First, sign into the State Intellectual Property Office of P.R.C website, the United States Patent and Trademark Office website, the German Patent and Trademark Office website, the French Industrial Property Office website, the Korea Intellectual Property Rights Information Service website and the Japan Patent Office website, then isometric randomly chose 3838 patents granted in 1994 from six countries, finally count the maintenance time of 3838 patents from every country. The analysis results show that the quantity of patent , the maintenance time of which is over ten years, is 1156 in China, 2485 in America, 1602 in German, 1986 in France, 1485 in Korea and 1957 in Japan by the end of 2014. It can be seen that the quantity of patent that the maintenance time is over ten years is obvious lower than other developing countries. Therefore, China still is not a powerful patent country. We must intensive research how to extend the maintenance time if China wants to bloom into a powerful patent country.

The maintenance time is influenced by multiple factors, the research literature from home and abroad is rarely so that we could not find literature which analyzes the relationship between examination time and maintenance time and reasons behind the relationship.

A literature published in China has put forward the influence factors of the maintenance time of patent. There are the patent information, the degree of patent commercialization, the patent system, the patent authorized institution, the patent management and the patent strategy. All of these influence factors primarily include the country of holder, the mold of holder, the techno-sphere, the 
patent family, the annual fee of patent, the scope of patent protection and so on ${ }^{[1]}$. A literature has drawn a conclusion that the examination time is inversely proportional to the number of years that the rights of patent is invalid due to the annual fee. When the examination time decreases 1 year, the maintenance time will increase 0.128 year $^{[2]}$. Brown and Harhoff researched the relationship between the country of holder and the maintenance time of patent in $20 \mathrm{th}^{[3,4]}$. Nakanish researched the relationship between the techno-sphere and the maintenance time of patent in $2008^{[5]}$. Liua researched the relationship between the patent family and the maintenance time of patent in $2008^{[6]}$. Gronqvist researched the relationship between the mold of holder and the maintenance time of patent in $2009^{[7]}$. However, there is still no one analyze the reasons between the maintenance time and the examination time specially.

Based on the research of predecessors, this paper will analyze the relationship between the maintenance time and the examination time, and then we will analyze the reasons behind the relationship, so that we can obtain the methods how to extend the maintenance time of patent.

\section{Data Sources}

The number of patents application of three-kind patents averagely increase $20 \%$ above every year. The number of application and authorization of three-kind patents achieved 2377000 and 1313000 in 2013. In order to analyze the relationship between the maintenance time and the examination time, if we statistics the data one by one, the workload will be heavy. So the data bases on patents granted in one year.

First, sign into the State Intellectual Property Office of P.R.C website, and then isometric randomly chose 3838 patents granted in 1994, finally count the maintenance time and the examination time of 3838 patents by the end of 2014 as the samples. On the one hand, we can research the whole process of protection and the reason of invalidation of patent because that the duration of patent is 20 years, so that we can reach the result of the relationship between the maintenance time and the examination time. On the other hand, the data of 2014 is new .

\section{The Relationship between the Examination Time and the Maintenance Time of Patents}

Based on the literature review, the relationship strength on the examination time and the maintenance time of patents were concluded. However, the linear-regression analysis was established on the macro-perspective. This paper mainly analyzes the relationship on the micro-perspective.

\subsection{Based on the Perspective of the Percentage Variation of the Patent Number}

The analysis on the relationship bases on the every patent number under different maintenance time as a percentage of the total patent number under different examination time. For example, when the examination time is one year, the patent number when the maintenance time is over ten year as a percentage of the total patent number, can reflect the possibility that the maintenance time is over ten year under different examination time. The higher the percentage is, the longer the maintenance time is. So if there is a negative linear correlation between the examination time and the maintenance time of patents, the percentage will be lower when the examination time is longer.

The figure 1 mainly analyzes the percentage variation of patent number when the maintenance time is over 10 years and 15 years. The reason is that the maintenance time from 10 years to 15 years belongs to the transitional period, and the maintenance time which is over 15 years is relatively long. 


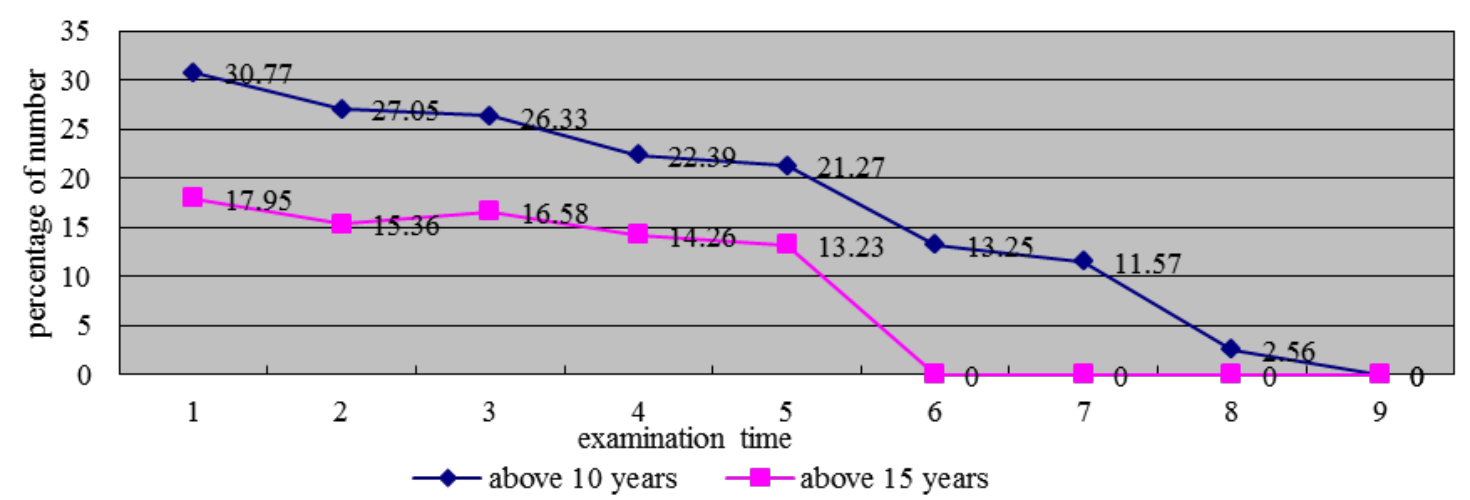

Fig. 1 The percentage variation of patent number when the maintenance time is over 10 or 15 years

From figure 1, whatever the maintenance time is over 10 years or 15 years, the trends of the percentage are down. So we can conclude that the examination time is negative relative with the maintenance time. Second, the trend of the percentage when the examination time is 3 years appears rise but still is down after the rise under the variation curve that the maintenance time is over 15 years, which does not reflect the negative relationship. Third, whatever the maintenance time is over 10 years or 15 years, the percentage is under $50 \%$, which reflect that the patent which the maintenance time is over 10 years is not much. So the maintenance time in China is not long.

3.2 The Relationship Analysis between the Maintenance time and the Examination time of Patents Based on the Perspective of the Variation of the Patent Number

Above mentioned analysis shows that the examination time is negative with the maintenance time, and the possibility that the maintenance time is 15 years will be higher when the examination time is 3 years from the perspective of the percentage variation of the patent number, and the maintenance time is not long for the whole. Now, we analyze the patent number under different examination times under two circumstances that the maintenance time within 10 years and over 10 years. The greater the patent number is, the longer the maintenance time is. The relationships are showed in figure 2 and figure 3.

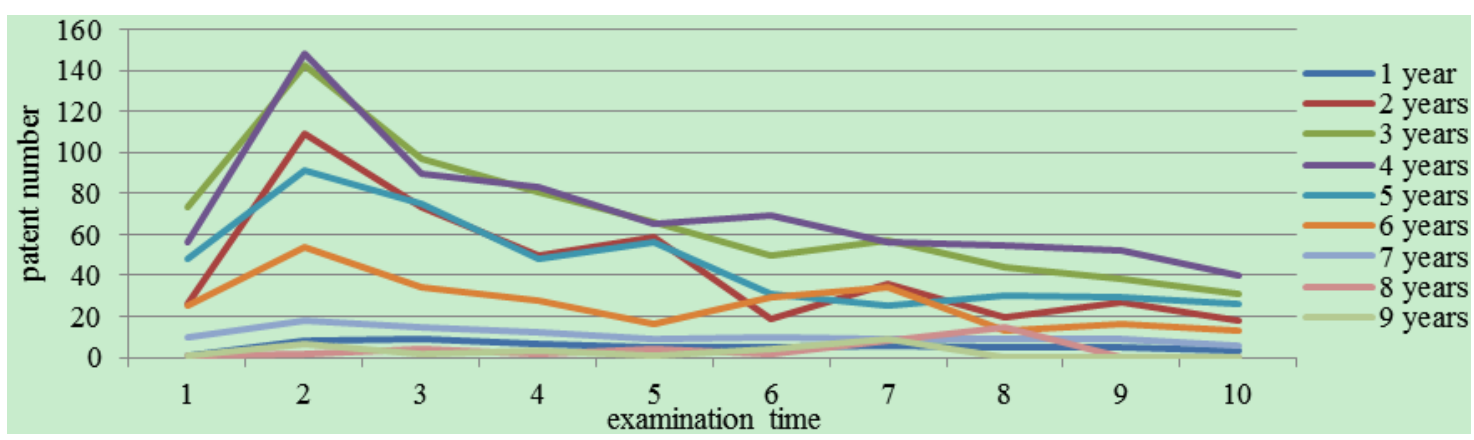

Fig. 2 The variation of the patent number when the maintenance time is within 10 years

From the figure 2, when the maintenance time is within 10 years, the patent number under different examination time shows the trend to rise first and then fall. On the one hand, when the examination time is 2-5 years, the patent number under different maintenance time all along is much than other examination time, which reflects that the examination time assembles in 2-5 years whatever the maintenance time is. On the other hand, when the maintenance time is 1-3 years, the patent number under different examination time all along is much than other maintenance time, which reflects that the maintenance time assembles in 1-3 years whatever the examination time is. 


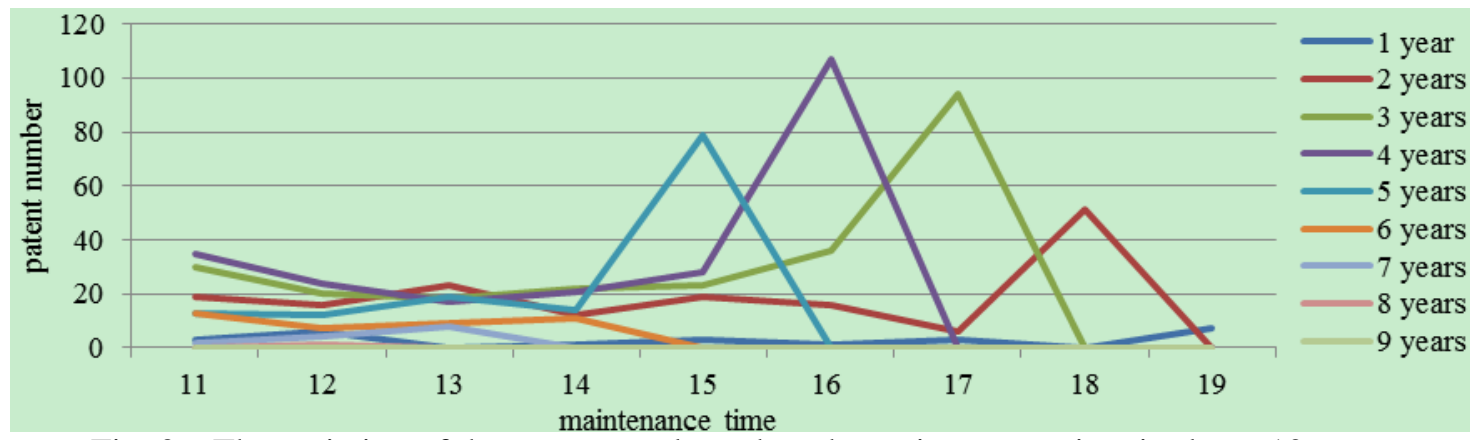

Fig. 3 The variation of the patent number when the maintenance time is above 10 years

From the figure3, the first variation of the patent number is not obvious but then appears up and down significantly when the maintenance time is over 10 years. As the examination time is 2-5 years, the patent number when the maintenance time is $15-19$ years is more than other maintenance time, which reflect the possibility that the maintenance time is over 15 years is maximum when the examination time is 2-5 years.

\subsection{The Relationship Analysis between the Maintenance Time and the Examination time of Patents Based on the Perspective of the Examination Time within 2-5 Years}

From figure 1, 2and 3, we can conclude that the examination time of patents assembles within 2-5 years and the possibility that the maintenance time is over 15 years is maximum. The maintenance time of patents assembles within 1-3 years. Now, we begin to analyze the relationships from the perspective that the patent number under different maintenance time as a percentage of the total samples. The total samples are 3631 except for the invalid samples. Because the cardinal number of percentage is the total samples, so the higher the percentage is, the higher the possibility that the maintenance time appears under one examination time is. The relationships can be showed in table 1.

Table 1 Patent number every examination time correspond to under different maintenance time

\begin{tabular}{c|c|c|c|c|c|c|c|c|c|c|c|c|c|c|c|c|c|c}
\hline ET & 1 & $\%$ & 2 & $\%$ & 3 & $\%$ & 4 & $\%$ & 5 & $\%$ & 6 & $\%$ & 7 & $\%$ & 8 & $\%$ & 9 & $\%$ \\
\hline $1-4$ & 25 & 0.7 & 258 & 7 & 394 & 10.8 & 377 & 10.4 & 262 & 7.2 & 141 & 3.9 & 55 & 1.5 & 9 & 0.2 & 13 & 0.4 \\
\hline $5-8$ & 21 & 0.6 & 134 & 3.7 & 217 & 6 & 245 & 6.7 & 142 & 3.9 & 92 & 2.5 & 37 & 1 & 29 & 0.8 & 14 & 0.4 \\
\hline $9-12$ & 17 & 0.5 & 80 & 2.2. & 119 & 3.3 & 151 & 4.2 & 80 & 2.2 & 49 & 1.3 & 21 & 0.6 & 1 & 0.1 & 0 & 0 \\
\hline $13-16$ & 5 & 0.1 & 70 & 1.9 & 99 & 2.7 & 173 & 4.8 & 112 & 3.1 & 20 & 0.6 & 8 & 0.2 & 0 & 0 & 0 & 0 \\
\hline $17-19$ & 10 & 0.3 & 57 & 1.6 & 94 & 2.6 & 0 & 0 & 0 & 0 & 0 & 0 & 0 & 0 & 0 & 0 & 0 & 0 \\
\hline Total & 78 & 2.2 & 599 & 16.4 & 923 & 25.4 & 946 & 26.1 & 596 & 16.4 & 302 & 8.3 & 121 & 3.3 & 39 & 1.1 & 27 & 0.8 \\
\hline
\end{tabular}

Note: (1)ET: The examination time of patents (2)MT: The maintenance time of patents

First, the examination time which the top four percentage of patent number correspond to is 3,4 , 5 and 2 years, the maintenance time all is within 1-3 years, which reflects that the examination time always within 2-5 years and the maintenance time always within 1-3 years.

Second, when the examination time is $2-5$ years, the percentage of patent number is over $2 \%$. When the maintenance time is 13-19 years, the percentage is over 3. All of this reflects that when the examination time is within 2-5 years, the possibility that the maintenance time will be within 13-19 years is higher.

Thirdly, when the examination time is $1,6,7,8$ and 9 years, the percentage of the patent number all appear the circumstance that the percentage is below $1 \%$, and when the maintenance time is 13-19 years, the percentage is all below $0.7 \%$. It thus appears that when the examination time is 1 year and within 6-9 years, the possibility that the maintenance time will be within 13-19 years is lower.

Finally, when the examination time is 4 years, the percentage (except for the top four percentage) is higher than the percentage under the other examination time which the different maintenance time correspond to, and the percentage all is above 4\%. It shows that the possibility that the examination time is 4 years is maximum, and the maintenance time is maximum under this examination time.

It follows from this that when the examination time is within 2-5 years, the possibility that the maintenance time will be within 1-3 years is maximum, which reflect that the maintenance time of 
China is short as a whole. When the examination time is 4 years, the possibility that the maintenance time is long reaches the maximum.

\section{The Analysis on the Reasons of the Relationship between the Examination Time and the Maintenance Time of Patents}

We always base on the patent system and the essence of the patent if we analyze the reasons of the relationships between the examination time and the maintenance time. A patent always undergo four-phase procedure that is the application, the examination, the authorization and the employment which the policy and technology market have a far-reaching influence on. So this paper analyzes the reasons from the perspective of the term of the protection, the policy support, the technology market and the censorship.

\subsection{The Perspective of the Patent Protection Term}

The term of patent protection in China is 20 years, which calculated from the date of the application. The maintenance time of patent is calculated from the date of the authorization. The examination time is calculated from the date of the application. So the sum of the examination time and the maintenance time is 20 years. Except for other influencing factors, the relationship under ideal condition between the examination time and the maintenance time can be showed by the figure 4.

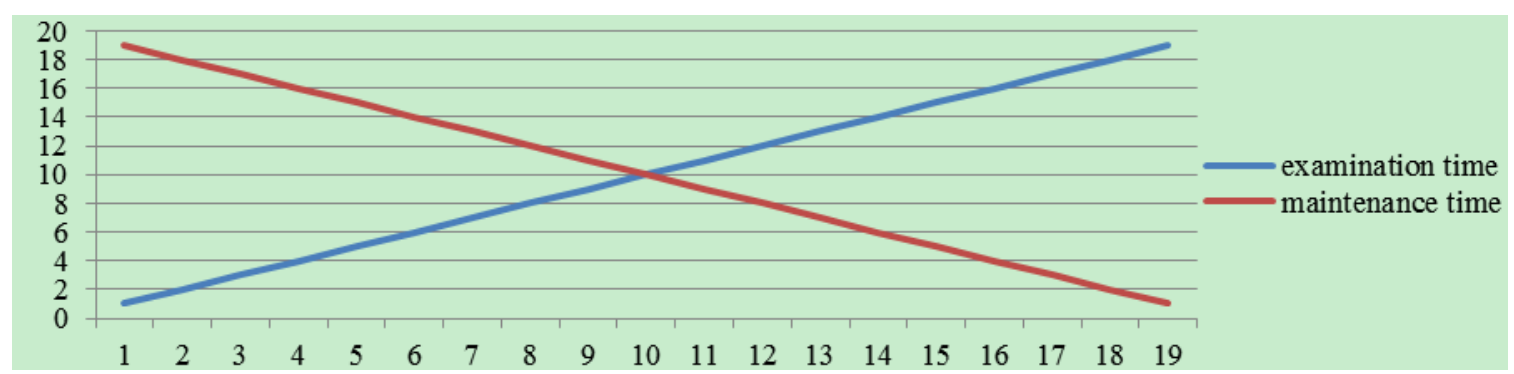

Fig. 4 The ideal relationship between the examination time and the maintenance time

The examination time refer to the duration from the date that the technology solution is applied to the date that the technology solution is granted. The maintenance time refer to the duration from the date that the patent is granted to the date that the right of patent is abandoned or invalidated or terminated. The longer the examination is, the shorter the date from the authorization date to invalidation date is. Hence, the maintenance time is inevitably negative with the examination time from the perspective of the term of the protection. This verifies that when the maintenance time is above 15 years, the initial point of the examination time that the patent number is 0 is 6 years, and when the maintenance time is above 10 years, the initial point of the examination time that the patent number is 0 is 9 years in figure 1.

\subsection{The Support Perspective of the Patent Policy}

The intellectual property law is regarded as a benefit distribution, law choice and integration between the monopolized interest of the intellectual property owner and the public interest. The patent fee is one of the most direct embodiment of this. The applicant can be access to exclusive rights by paying a fee.

In order to apply for or maintain the patent, we should pay the patent fees which include application fee, licensing fee, annual fee and agent fee. The annual fee not is invariable but terraced increase as the growth of the protective time. The first 3 annual fees can be maximum reduction of $85 \%$ for personage and $70 \%$ for enterprise. Meanwhile, local government subsidizes various innovative subjects to apply patent by fiscal appropriation which leads to the reduction of the cost of the patent application, sometimes even overflow the cost. When the applicants make a profit from the fiscal appropriation about patent, the motivation of applicant will be change. They will apply patent for profit not for the protection of the technology market. In such a motive of domination, the applicants maybe take advantage of the loophole of system and policy to apply crap patent which has no innovative content. 
According to the balance payments theory, due to the policy breaks and government funding, some patents can't make profit from market, but patent holder will continue to maintain the patent to be valid because the cost is lesser than profit after the various supports. This verifies that whatever the examination time is, the maintenance time of most patent will be within 2-3 years, and the possibility that the examination time is within $2-5$ years is relatively high and the maintenance time of this patent is mostly within 1-4 years in figure 2 and table 1.

\subsection{The Perspective of the Patent Market}

In the situation of marketing economy, large collection of patents has formed the huge patent market which refers to the market mainly through patent as commodity trading. In 2005, Jilin, Wuhan emerge "patent supermarket" which tries to settle the problem of patent market exports. In 2006, in order to cultivate patent market and market service system of patent technology transfer, trade and implement the transformation, SIPO developed the national patent technology exhibition transaction platform project and approved a batch national patent technology exhibition center so that there could be a high integrity and low cost of the permanent show trading place for inventor and investor.

The patent as a technical solution is to settle the technical problem. It is operational and practical. Who own the exclusive right of a technology, who will be the market leader of this field of technology? The possibility that this patent forms a new technology market will rise greatly if a patent is accessible to transfer. Therefore, which technology solution can be authorized firstly that settles the some technology problem, the possibility that it occupies the market will be higher and the prospect benefit will be higher.

The overlong examination time tends to make a technology confront the crisis of being eliminated by market when this technology is authorized so that this patent can't achieve higher prospect benefit. In the end, this patent can't maintain the balance of payments. The maintenance time mainly depends on the result of balance of payments. The longer the examination time is, the shorter the maintenance time is, and the prospect benefit will decline. Whether continue to maintain the patent exists certain risks. When the prospect benefit decline, the risk will increase and the possibility that the patent holder continues to maintain will decline. This verifies the reason why the examination time is negative with the maintenance time.

\subsection{The Perspective of the Examination System}

According to the article 34 and 35 of patent law, the longest date of the preliminary examination calculated from the date of application is 18 month, and substantive examination is conducted within 3 years calculated from the date of application. So the date from the application to authorization as a general rule will be within 5 years which verifies that the reason why the percentage is $84.4 \%$ when the examination is within 2 to 5 years in table 1 . In addition, the larger the cardinal number is, the greater the possibility that the maintenance time is long is, which verifies that when the examination time is within 2-5 years, the possibility that maintenance time is within 13-19 years is greater than other examination time.

The patent law just provides the date of preliminary examination and the starting time of substantive examination, the date of substantive examination is not provided. The influence factors of examination time have application document, the efficiency of the censors, audit program and the patience of applicant. The factors will indefinitely delay the date of substantive examination which leads to abnormal situation that the examination time is above 5 years. The patent percentage when the examination time is above 5 years just is about $13.7 \%$ in table 1 . The possibility that the examination time is above 5 years is low, so the possibility that the maintenance time is long is low. For the same reason, the patent percentage is $2.15 \%$ when the examination time is 1 years in table 1 , constrained the date of patent examination and the skill of patent examination, so the possibility that the maintenance time is long is low.

\section{Conclusion and Enlightenment}

The maintenance time is a mirror of the patent strengthens of one country and it's important for China to become a patent power country. In conclusion, the sum of the examination time and the 
maintenance time is 20 years, so the negative relationship necessary being between them. Secondly, most patents maintain within 3 years and the examination time mainly is within 2 to 5 years. Thirdly, the probability that the maintenance time is long will be higher when the examination time is within 2 to 5 years. Finally, the probability that the maintenance time is long will be highest when the examination time is 4 years.

Due to the sum of the examination time and the maintenance time is 20 years, with other conditions unchanged, so the longer the examination time is, the shorter the maintenance time is. If we want to extend the maintenance time, what we can do is to shorten the examination time. But it not means to infinitely shorten the examination time because of the reality, which the patent has strong technicality, so novelty, invention and practical application is necessary to be examined. Due to the limited skill of examination, SIPO can't finish examination in a short time. Hence, we should avoid the unlimited extension of examination time because of the influence factors apart from the patent technology itself. Then, it is good to control the examination time within 2-5 years, which can extend the maintenance time. How to avoid unlimited extension of examination time can be showed by following points.

In the matter of audit program, we propose revise the patent law so that the date of examination is explicitly stipulated. It is sensible to supervise the patent examination effectively by legal restraint so that we can avoid the contraction of maintenance time due to the excessive time of examination and the depression of market.

In the matter of examiner, we suggest that establish and improve system of examiner. We can establish the test system of examiner like the National Patent Agent Qualification Examination. The examiner should improve the quality of their professional competence and strengthen professional conduct. The crap technology should be put outdoor of patent from the source.

In the matter of patent application, patent ability should be strictly regulated and the applicant scope should be strictly limited. The patent application must be carried out by specialized patent agency institute, which can avoid the extension of examination time due to the problems that the applicant is blind to application process and the application document is not comprehensive enough.

To sum up, we can redefine and improve the system of audit program, examiner and patent application lead to avoid the extension of examination time due to the reason of non-patented technology itself. Consequently, the maintenance time of patent is extended to some extent.

\section{Acknowledgment}

This research was supported by the National Natural Science Foundation of China (batch number: 71373221)

\section{References}

[1] Song Shuang. The Factors Affecting the Patent Maintenance Time of China from the Point of the Quality of patent[J]. Library and Information Service, 2013(4):96-100. (In Chinese)

[2] Qiao Y. The factors affecting the patent maintenance time[J]. Science Research Management, 2011.

[3] William H Brown. Trends in patent renewals at the United States patent and trademark office[J]. World Patent Information, 1995, 17(4):225-234.

[4] Harhoff D, Narin F, Scherer F M, et al. Citation Frequency and the Value of Patented inventions [J]. Review of Economics \& Statistics, 1999, 81(3):511-515.

[5] Nakanishi Y, Yamada S. Measuring the Rate of Obsolescence of Patents in Japanese Manufacturing Firms[J]. Mpra Paper, 2008.

[6] Liu K, Arthurs J, Cullen J, et al. Internal sequential innovations: How does interrelatedness affect patent renewal?[J]. Research Policy, 2008, 37(5):946-953. 
[7] Grönqvist C. The private value of patents by patent characteristics: evidence from Finland[J]. Journal of Technology Transfer, 2009, 34(34):159-168. 